\title{
Estimating Economically Optimal Levels of Nitrogen Fertilizer in No-Tillage Continuous Corn
}

\author{
Alexis H. Villacis ${ }^{1 \star *}$ (1D, A. Ford Ramsey ${ }^{3}$, Jorge A. Delgado ${ }^{2}$ and Jeffrey R. Alwang ${ }^{3}$ \\ ${ }^{1}$ Morrison School of Agribusiness, W.P. Carey School of Business, Arizona State University, Mesa, AZ, USA, ${ }^{2}$ USDA-ARS Soil \\ Management and Sugarbeet Research Unit, Fort Collins, CO, USA and ${ }^{3}$ Department of Agricultural and Applied Economics, \\ Virginia Tech, Blacksburg, VA, USA \\ *Corresponding author. Email: alexis.villacis@asu.edu
}

\begin{abstract}
Stochastic plateau production functions provide improved fertilizer recommendations based on multi-year agronomic experiments where weather and other stochastic variables change over time. This research assesses the profitability of no-tillage corn production in northeastern Colorado and determines economically optimal nitrogen fertilizer rates. It also proposes an alternative parameterization of the linear response stochastic plateau model which provides a robustness check against traditional parameterizations. Results show the current use of nitrogen fertilizer in the area exceeds estimated economically optimal levels. This suggests that a reduction in nitrogen use could increase expected profits and simultaneously reduce environmental costs.
\end{abstract}

Keywords: corn; linear response stochastic plateau; Monte Carlo; nitrogen; no-tillage; non-linear mixed-effects models; random parameters; switching regression

JEL Classifications: C12; D24; Q10; Q12; Q14

\section{Introduction}

In accordance with von Liebig's Law of the Minimum, researchers frequently use plateau production functions to empirically assess the response of crop yields to inputs. Recent studies following Tembo et al. (2008) have focused on estimating plateau production functions with stochastic plateaus. Such models incorporate random effects to capture the influence of stochastic events - such as pests, weed pressure, and weather-on crop yield response. Allowing for yearly stochastic variations in the plateau, this approach has yielded an accurate model of plant response and producers' profit expectations and has since been extended to include additional random parameters and non-linearities (Tumusiime et al., 2011). While the stochastic plateau production function has been applied to a number of different crops including wheat, winter rye, and cotton (Biermacher et al., 2009; Harmon et al., 2016; Roberts et al., 2011; Taylor et al., 2010), there are relatively few applications in corn yields and most of them have been conducted in Tennessee (Boyer et al., 2013, 2014, 2015).

We use the stochastic plateau model to estimate irrigated no-tillage corn yield response functions to nitrogen in northeastern Colorado. Delgado and Bausch (2005) suggest that farmers in Colorado may apply excessive amounts of nitrogen fertilizer during crop cultivation, which can cause unreasonably high levels of nitrates in groundwater. The overuse of fertilizer also reduces producers' profits by way of increased input costs. Because of the plateau form of the production function, an increase in the use of inputs does not necessarily translate into a marginal change in output. Based on these observations, we determine economically optimal nitrogen rates in

(C) The Author(s) 2020. This is an Open Access article, distributed under the terms of the Creative Commons Attribution licence (http:// creativecommons.org/licenses/by/4.0/), which permits unrestricted re-use, distribution, and reproduction in any medium, provided the original work is properly cited. 
northeastern Colorado, as relatively little is known about optimal nitrogen levels of irrigated no-tillage continuous corn in the study area. We use data from a long-term irrigated no-tillage continuous corn study conducted in Fort Collins, Colorado. This rich data set allows us to evaluate year-to-year weather variability as well as the cumulative effects of the no-tillage practice on corn profitability.

In what follows, our primary objectives include (1) estimating the profit-maximizing nitrogen fertilizer rates and yields for irrigated continuous corn under a no-tillage system, and (2) analyzing expected net returns using the profit-maximizing nitrogen fertilizer rates and yields. Expected profits are estimated using standard methods of Monte Carlo integration, and economically optimum nitrogen rates are calculated using non-linear optimization. In addition, we propose and develop an alternative parameterization of the stochastic plateau model that follows a switching regression (SR) format. This alternative parameterization is proposed as a tool for checking the robustness of the results obtained with the classic stochastic plateau model. Moreover, this alternative can help researchers check if the optimization algorithm used to maximize the likelihood function converged to a local instead of a global optimum. We compare the goodness of fit of the alternative parameterization to the classic stochastic plateau model as a point of reference in the application to no-tillage corn.

Lastly, we compare the reported use of nitrogen among local corn producers and recommended levels from extension services to optimal nitrogen levels estimated in this study. The results of this comparison suggest the overuse of nitrogen with negative impacts on producer profits and presumably poorer environmental outcomes. This suggests that continued work in optimal nitrogen recommendations is warranted, particularly if longer-term experiments allow researchers to bring the advantages of the stochastic plateau production function to bear. By incorporating more variation in weather and other stochastic variables affecting crop response through extended data, agricultural economists will be able to provide more accurate input recommendations and assessments of the economic impacts of input use.

\section{Conceptual and Econometric Framework}

A risk-neutral producer's objective is to maximize expected net returns from corn production:

$$
\begin{aligned}
& \max _{N} E(\pi)=\mathrm{p} E(y)-\mathrm{rN} \\
& \text { s.t. } \quad y=\mathrm{F}(N), \quad N \geq 0
\end{aligned}
$$

where $E(\pi)$ is the expected net return (\$/ha) for the producer, $p$ is the corn price $(\$ / \mathrm{kg}), r$ is the nitrogen fertilizer price $(\$ / \mathrm{kg}), N$ is the quantity of fertilizer applied $(\mathrm{kg} / \mathrm{ha})$, and $E(y)$ is the expected yield $(\mathrm{kg} / \mathrm{ha})$.

In the case of yield response to a single input, Tembo et al. (2008) give the general form of the linear response stochastic plateau (LRSP) production function as:

$$
y_{i t}=F\left(N_{i t}\right)+\varepsilon_{i t}+u_{t}
$$

where

$$
F\left(N_{i t}\right)=\min \left\{\beta_{0}+\beta_{1} N_{i t}, P_{m}+v_{t}\right\}
$$

and $t$ indexes over time, $i$ is the plot or location, $y_{i t}$ is the yield in plot $i$ in year $t, N_{i t}$ is the nitrogen applied to plot $i$ in year $t, \varepsilon_{i t} \sim N\left(0, \sigma_{\varepsilon}^{2}\right)$ is a random error term, $u_{t} \sim N\left(0, \sigma_{u}^{2}\right)$ is an intercept year random effect, and $v_{t} \sim N\left(0, \sigma_{v}^{2}\right)$ is a plateau year random effect. In the Tembo et al. (2008) specification, the error and random effects are assumed to be independent. The fixed-effect parameters are the intercept $\beta_{0}$, the slope $\beta_{1}$, and the average plateau yield $P_{m}$.

Tumusiime et al. (2011) expanded the model of Tembo et al. (2008) by allowing for additional randomness in the slope parameter and relaxing the assumption of independence in the variance parameters. $F\left(N_{i t}\right)$ is then 


$$
F\left(N_{i t}\right)=\min \left\{\beta_{0}+\left(\omega_{t}+\beta_{1}\right) N_{i t}, P_{m}+v_{t}\right\}
$$

and $\omega_{t} \sim N\left(0, \sigma_{\omega}^{2}\right)$ is the slope random effect. The random effect (variance) parameters $\omega_{t}, v_{t}$, and $u_{t}$ are normally distributed and allowed to be correlated.

The addition of these random effects and their correlation helps the production function capture the influence of stochastic events on the yield response. ${ }^{1}$ A closed-form for the likelihood function is not available for both model specifications, but it can be estimated using Gaussian quadrature approximations. Both model specifications can be estimated using frequentist techniques for the estimation of non-linear mixed-effects models. Ouedraogo and Brorsen (2017) detail an alternative Bayesian approach.

These stochastic plateau specifications are highly flexible and can also incorporate additional non-linearities in yield response. However, the use of the most flexible specifications is often limited in practice by the relatively short samples available from most agricultural experiments. In addition, estimating the expectation of $y_{i t}$ requires the use of numerical integration. Using the estimates of the parameters of the production function in equation (4), we calculate $E\left(y_{i t}\right)$ using standard methods of Monte Carlo integration.

\subsection{An Alternative Parameterization}

We propose and develop an $\mathrm{SR}^{2}$ type of plateau production function with random effects. This alternative parameterization of the linear stochastic plateau model is presented as a tool for the robustness check of the main results obtained with the LRSP. It also has the objective of helping researchers avoid local optima when estimating non-linear mixed-effects models. The SR has the direct interpretation of a stochastic level of nitrogen required to reach the yield plateau. It, therefore, represents a complementary specification to the LRSP.

Following Maddala and Nelson (1974), the SR specification for yield response to a single input can be expressed in the same fashion as equation (2). In this case, $F(N)$ has a threshold point $\beta_{2}$ that includes a random effect such that

$$
F(N)= \begin{cases}\left(\beta_{0}+u_{t}\right)+\beta_{1} N_{i t} ; & N_{i t}<\left(\beta_{2}+v_{t}\right) \\ \left(\beta_{0}+u_{t}\right)+\beta_{1}\left(\beta_{2}+v_{t}\right) ; & N_{i t} \geq\left(\beta_{2}+v_{t}\right)\end{cases}
$$

The threshold point $\beta_{2}$ is the minimum nitrogen level necessary to reach the plateau yield. As shown in equation (5), the threshold point is an unknown parameter determined by the data. $v_{t} \sim N\left(0, \sigma_{v}^{2}\right)$ represents the $\beta_{2}$ year random effect which shifts the minimum nitrogen level necessary to reach the plateau yield and consequently causes the plateau to shift up or down. Like in the LRSP, here $u_{t} \sim N\left(0, \sigma_{u}^{2}\right)$ is the intercept year random effect that allows the whole function to shift up or down. Without loss of generality, we can assume no correlation among $u_{t}$ and $v_{t}$.

Like the LRSP, the SR is an empirical embodiment of von Liebig's Law of the Minimum and describes a production function where the corn yield increases in a linear fashion with the addition of nitrogen until the threshold point $\beta_{2}$ is reached. This threshold point $\beta_{2}$ defines the yield plateau; beyond the threshold point, additional nitrogen use will not increase the corn yield.

\footnotetext{
${ }^{1}$ The intercept random effect $u_{t}$ allows the production function to shift up or down and represents effects from insects, diseases, poor stands, heat, freeze damage, and other weather effects. The plateau random effect $v_{t}$ shifts the yield plateau potential and represent effects from other limiting inputs. The slope random effect $\omega_{t}$ represents effects from nitrogen productivity including losses from leaching, soil, or weather.

${ }^{2}$ Makowski and Lavielle (2006) estimated a response model using a stochastic approximation of the expectation maximization algorithm defined into two hierarchical stages: (1) a within site-year yield response to applied fertilizer and (2) a between site-year yield response to applied fertilizer. The first stage used a linear-plus-plateau function (LP) defined by a switching regression (SR). The SR proposed here is closer to the specifications proposed in Cerrato and Blackmer (1990) and Bullock and Bullock (1994).
} 
(a)

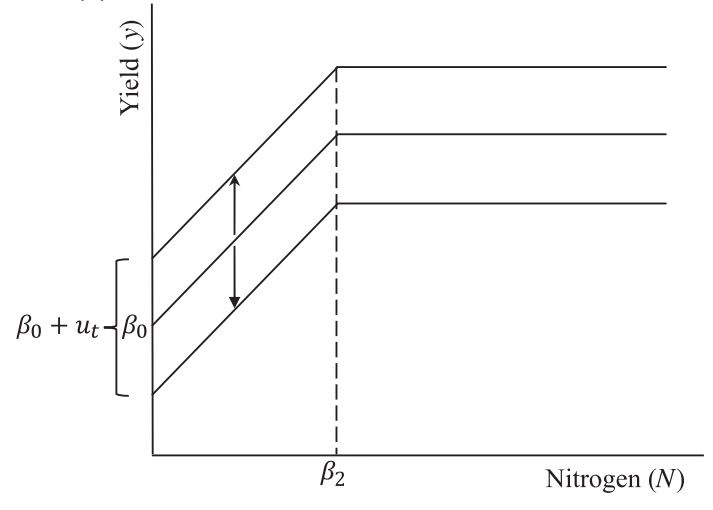

(c) (b)

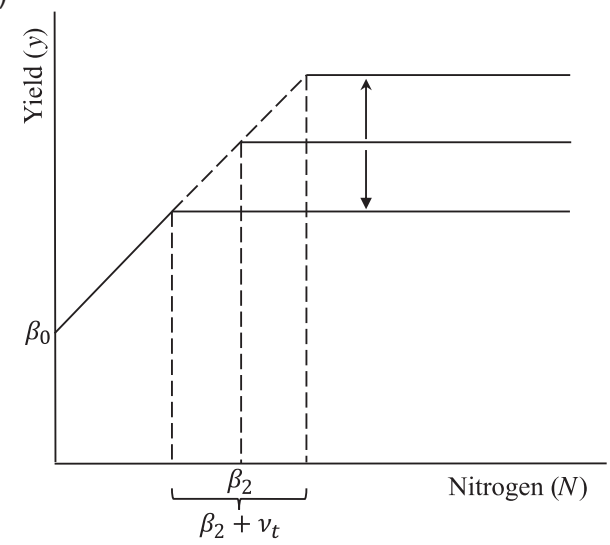

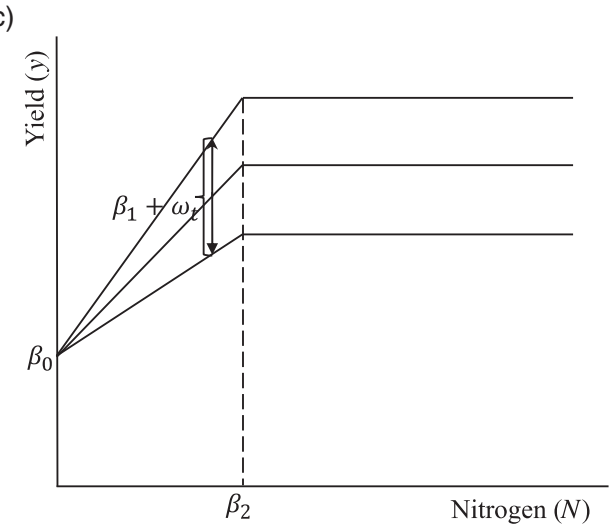

Figure 1. Potential shifts induced by the random effects.

By including random effects for all of the parameters, equation (5) becomes:

$$
F(N)= \begin{cases}\left(\beta_{o}+u_{t}\right)+\left(\beta_{1}+\omega_{t}\right) N_{i t} ; & N_{i t}<\left(\beta_{2}+v_{t}\right) \\ \left(\beta_{o}+u_{t}\right)+\left(\beta_{1}+\omega_{t}\right)\left(\beta_{2}+v_{t}\right) ; & N_{i t} \geq\left(\beta_{2}+v_{t}\right)\end{cases}
$$

which is similar to the model specification presented in equation (4). Likewise, the variance parameters $\omega_{t}, v_{t}$, and $u_{t}$ are assumed to be correlated and normally distributed. Allowing for nonzero covariances permits a richer set of relationships between the random effects.

The key difference between the SR parameterization and the classic LRSP is the selection of parameters of interest. LRSP treats the plateau yield, $P_{m}$, as a parameter and adds the random effect $v_{t}$ to $P_{m}$ to account for stochastic effects in the plateau itself. In doing so, LRSP captures most of the stochastic variation of the plateau yield but does not provide the researcher with information on how much of this variation can be attributed to nitrogen use. In contrast, SR treats the minimum nitrogen level to reach the plateau yield as a switching parameter. The yield plateau and its variation are then influenced and determined by this parameter and its random effect $v_{t}$. This parameterization is an advantage if one wishes to explore how much of the yield plateau variation can be attributed to nitrogen use.

The impact of the random effects of this parameterization can be shown graphically. Figure 1(a) represents the shifts caused by random effect $u_{t}$, which adjusts the production function across the entire domain of the input. The adjustment in terms of yield is constant across the level of nitrogen. Figure 1(b) shows the plateau shifts caused by the random effect $v_{t}$ and Figure 1(c) 
represents the plateau shifts caused by the random effect $\omega_{t}$. As it is evident from the figures, the plateau can shift over time due to a number of factors, some of which are unobservable to producers and uncontrollable even in experimental settings. The random variation of the plateaualso viewed as the maximum yield one can obtain due to a limiting input-leaves the producer with the task of determining the best use and management of nitrogen. Recognizing this task as being left to the producer, we estimate the alternative SR parameterization where $\beta_{2}$ is modeled as a parameter instead of $P_{m}$.

Similar to the LRSP, the estimation of $E\left(y_{i t}\right)$ for the SR parameterization requires integration that must be solved numerically, and therefore, we use standard methods of Monte Carlo integration.

\section{Data}

We estimate and compare the nitrogen response models using experimental data collected from a long-term, no-tillage continuous corn study conducted at the Agricultural Research Development and Education Center (ARDEC), located in Fort Collins, Colorado. Nitrogen fertilization treatments included a control (no nitrogen) plus eight treatment levels $(34,68,101,134,168,202,224$, and $246 \mathrm{~kg} / \mathrm{ha}$ ). ${ }^{3}$ All plots were irrigated with a linear-move sprinkler system. The study was initiated in 2001 on a clay loam soil field, with one to two percent slope, that had previously been continuously cropped to corn for 8 years. Plots are close together and assumed to have soil uniformity. Data include 16 years of crop production, from 2001 to 2017, excluding 2008 due to an unusual and severe hailstorm that decimated the corn crop.

\section{Estimation}

We estimated the LRSP and SR specifications using MATLAB NLMEFIT, a solver for non-linear mixed-effects models. To calculate expected net returns and profit-maximizing nitrogen rates for the different tillage systems, we use the parameter estimates in combination with Monte Carlo methods. Ten thousand draws from the jointly normally distributed vector $\left[u_{t}, \omega_{t}, v_{t}\right] \sim N(0, \Omega)$ are generated using the respective variance/covariance estimates of the LRSP and SR parameterizations. Nitrogen applications varying by one unit over the interval $[0,246]$ are also generated. Yield expectations are computed for each of the simulated nitrogen applications evaluated at the 10,000 draws of the vectors of random effects. Finally, profitmaximizing nitrogen rates are calculated for each model using a traditional grid search since the problem involves only one choice variable. ${ }^{4}$

\section{Results}

First, we estimate the model specified in equation (3), henceforth designated LRSP1. The robustness of its results is checked with the alternative parameterization proposed in equation (5), henceforth designated SR1. We then extend both of the models by adding additional random effects. For LRSP1 this amounts to estimating the plateau function of equation (4), henceforth designated LRSP2. The robustness of LRSP2 is checked with the alternative parameterization proposed in equation (6), henceforth designated SR2. All results are presented in Table 1. Mean-squared errors (MSE) support the use of models with additional random effects over those without.

\footnotetext{
${ }^{3}$ For reference, $1 \mathrm{~kg} / \mathrm{ha} \approx 0.892 \mathrm{lb} / \mathrm{acre}$.

${ }^{4}$ For robustness, we also solved the nonlinear optimization problem of equation (1) using the MATLAB nonlinear programming solver. This solver calls the quasi-Newton algorithm using the BFGS quasi-Newton method with a cubic line search procedure.
} 
Table 1. Regression results for the LRSP and SR models

\begin{tabular}{|c|c|c|c|c|}
\hline \multirow[b]{2}{*}{ Parameter } & \multicolumn{4}{|c|}{ Models } \\
\hline & LRSP1 & SR1 & LRSP2 & SR2 \\
\hline \multirow[t]{2}{*}{ Intercept $\beta_{0}$} & $5,205.23$ & $5,232.91$ & $5,217.07$ & $5,204.52$ \\
\hline & $(204.29)$ & (191.70) & $(160.93)$ & $(167.49)$ \\
\hline \multirow[t]{2}{*}{ Slope $\beta_{1}$} & 31.05 & 30.42 & 30.66 & 30.77 \\
\hline & $(1.08)$ & $(1.06)$ & $(1.94)$ & $(1.81)$ \\
\hline \multirow[t]{2}{*}{ Nitrogen rate at Plateau $\beta_{2}$} & 149.86 & 151.39 & 152.37 & 153.38 \\
\hline & - & $(4.58)$ & - & $(7.36)$ \\
\hline \multirow[t]{2}{*}{ Yield Plateau $P_{m}$} & $9,859.02$ & $9,837.54$ & $9,888.40$ & $9,923.73$ \\
\hline & $(170.17)$ & - & $(179.82)$ & - \\
\hline \multirow[t]{2}{*}{ Intercept Random Effect $\sigma_{u}^{2}$} & 550,754 & 469,347 & 310,455 & 347,167 \\
\hline & $(71,507)$ & $(59,880)$ & $(94,043)$ & $(92,964)$ \\
\hline \multirow[t]{2}{*}{ Slope Random Effect $\sigma_{\omega}^{2}$} & - & - & 39.87 & 34.90 \\
\hline & - & - & $(12.75)$ & $(9.46)$ \\
\hline \multirow[t]{2}{*}{ Nitrogen rate at Plateau Random Effect $\sigma_{v}^{2}$} & - & 0.00 & - & 564.55 \\
\hline & - & (43.51) & - & $(172.18)$ \\
\hline \multirow[t]{2}{*}{ Yield Plateau Random Effect $\sigma_{v}^{2}$} & 344,787 & - & 413,414 & - \\
\hline & $(91,120)$ & - & $(110,322)$ & - \\
\hline MSE & 504,303 & 521,151 & 442,162 & 447,785 \\
\hline LogLikelihood & $-2,075.72$ & -2.069 .93 & $-2,062.21$ & $-2,062.79$ \\
\hline$n$ (number of observations) & 256 & 256 & 256 & 256 \\
\hline
\end{tabular}

Notes: LRSP1 model corresponds to equation (3). LRSP2 model corresponds to equation (4). SR1 model corresponds to equation (5). SR2 model corresponds to equation (6). Standard errors are in parenthesis. We used bootstrapping techniques to obtain consistent estimates of the corresponding standard errors for the random effects parameters. The predicted parameter $\widehat{\beta}_{2}$ for LRSP models and $\widehat{P_{m}}$ for SR models are calculated using the estimation results for each model.

Given that these are nested models, we also use likelihood ratio tests (Greene, 2017) to compare model 1 (restricted) and model 2 (unrestricted) within each parameterization. The value of the likelihood ratio statistic is 27.02 for LRSP and 14.28 for SR. The model with additional random effects in each parameterization has five more parameters than the model without, and hence the critical values of the test statistic are distributed chi-squared with $\chi_{(5,0.05)}^{2}=11.07$ and $\chi_{(5,0.01)}^{2}=15.09$. We reject the more parsimonious models at the $1 \%$ level of significance for LRSP and at the 5\% level of significance for SR. We conclude that allowing all parameters to have random effects, and assuming full correlation among the random effects, produces a model with superior fit. ${ }^{5}$ This result supports the findings of Makowski and Wallack (2002) and Tumusiime et al. (2011) in other crops.

Table 1 also captures some of the differences between the LRSP and SR model parameterizations. LRSP focuses on the estimation of the plateau yield $P_{m}$ and produces a coefficient and

\footnotetext{
${ }^{5}$ We tested several different specifications of the covariance matrix, and allowing all parameters to have random effects, and assuming full correlation among the effects, further reduces the mean-squared error and improves the likelihood values for both models. The random effects covariance matrix and correlation matrix of LRSP2 and SR2 are reported in Appendix 1.
} 


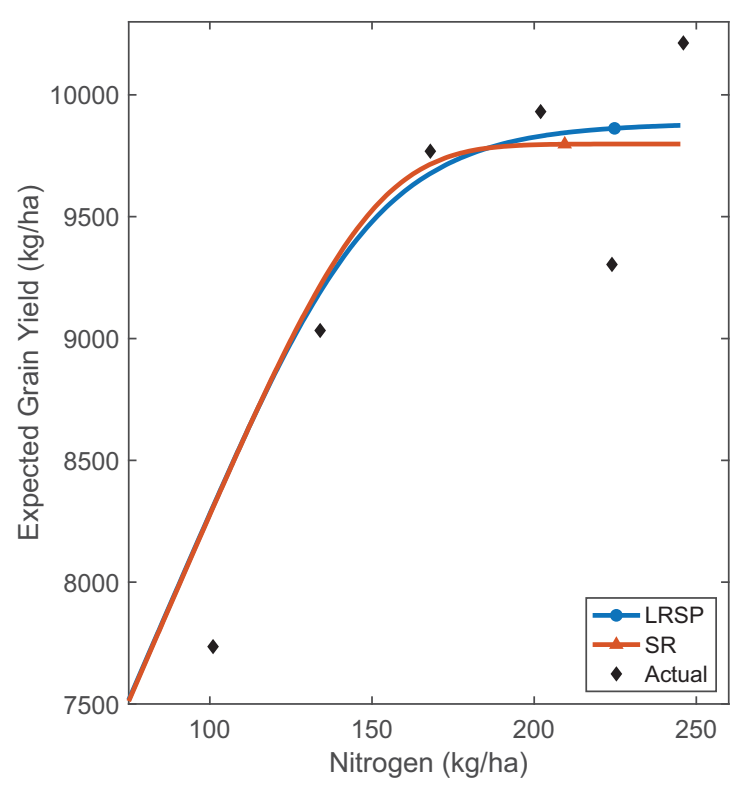

Figure 2. Expected grain yields for LRSP2 and SR2.

standard error for this parameter. The standard error facilitates hypothesis testing with respect to the plateau. Since the model does not estimate the value of the minimum nitrogen to reach the plateau, $\beta_{2}$, it must be predicted using the estimated parameters. If one is interested in the standard error of $\beta_{2}$, the delta rule or bootstrapping methods can be used to obtain measures of uncertainty. In contrast, the SR parameterization directly estimates the minimum nitrogen needed to reach the plateau and produces a coefficient and standard error. This represents a potential advantage of SR over LRSP, as the switching level of nitrogen may be of most interest to producers. Ultimately, it may be best to estimate both SR and LRSP and use the parameterization with the greatest likelihood value with the goal of avoiding local optima in the search algorithms used to estimate the models.

The nitrogen rate at the yield plateau is similar for models LRSP2 and SR2-152 kg/ha for LRSP2 and $153 \mathrm{~kg} /$ ha for SR2. The yield plateau is $9,888 \mathrm{~kg} /$ ha for LRSP2 and is marginally lower than the $9,923 \mathrm{~kg} / \mathrm{ha}$ estimated by SR2 (35 kg/ha difference that corresponds to $0.3 \%$ of the yield/ha). Adding a random effect to the slope and allowing a full correlation among the random effects did not cause considerable changes in the parameter estimates among our models. This might be explained by the nature of the experiment, as irrigation helps the soil to maintain the same level of moisture every year and reduce the impact of rainfalls (Laporte, Duchesne, and Wetzel, 2012). The moisture level for dryland and non-irrigated conditions depend heavily on rainfall, which can create larger random effects due to year-to-year variations in rainfall.

Boyer et al. (2013) also estimate corn response functions using experimental data from the U.S. and mixed-effects plateau models. They report no-tillage continuous corn response functions using a 6-year data set (2006-2011) from an experiment conducted at Milan, Tennessee. Although not directly comparable to the results of Boyer et al. (2013) due to differences in location and agronomic characteristics, the results in Table 1 are relatively close to their reported corn yield plateau of $9,912 \mathrm{~kg} / \mathrm{ha}$ and nitrogen rate at the plateau of $153 \mathrm{~kg} / \mathrm{ha}$.

Figure 2 shows the corn yield expectations for the simulated nitrogen applications using the LRSP2 and SR2 models. For reference, we also plot the actual yield averages. The expectations are similar for both the LRSP2 and SR2. 
Table 2. Expected profit-maximizing nitrogen rates $(\mathrm{kg} / \mathrm{ha})$, profit-maximizing yields $(\mathrm{kg} / \mathrm{ha})$, and net returns $(\$ / \mathrm{ha})$ for irrigated continuous-corn

\begin{tabular}{|c|c|c|c|c|}
\hline \multirow[b]{2}{*}{ Corn price } & \multirow[b]{2}{*}{ Result } & \multicolumn{3}{|c|}{ Nitrogen prices } \\
\hline & & $\$ 0.72$ & $\$ 0.96$ & $\$ 1.20$ \\
\hline \multirow[t]{3}{*}{$\$ 0.12$} & Profit Max. Nitrogen Rate $(\mathrm{kg} / \mathrm{ha})$ & 176 & 168 & 162 \\
\hline & Profit Max. Yield (kg/ha) & 9,732 & 9,678 & 9,620 \\
\hline & Expected Net Returns ( $\$ / \mathrm{ha})$ & 1,041 & 1,000 & 961 \\
\hline \multirow[t]{3}{*}{$\$ 0.20$} & Profit Max. Nitrogen Rate (kg/ha) & 189 & 182 & 176 \\
\hline & Profit Max. Yield (kg/ha) & 9,794 & 9,764 & 9,732 \\
\hline & Expected Net Returns ( $\$ /$ ha) & 1,823 & 1,778 & 1,735 \\
\hline \multirow[t]{3}{*}{$\$ 0.28$} & Profit Max. Nitrogen Rate $(\mathrm{kg} / \mathrm{ha})$ & 197 & 190 & 185 \\
\hline & Profit Max. Yield (kg/ha) & 9,820 & 9,799 & 9,777 \\
\hline & Expected Net Returns (\$/ha) & 2,608 & 2,561 & 2,516 \\
\hline
\end{tabular}

\subsection{Profit Analysis}

We estimate expected returns using partial budgets. Three different prices for $N$ are taken into account: $\$ 0.72, \$ 0.96$, and $\$ 1.20$ per $\mathrm{kg}$. These prices per $\mathrm{kg}$ are equivalent to prices of $\$ 300$, $\$ 400$, and $\$ 500$ per ton of 46-0-0 urea fertilizer, respectively. Likewise, we assume corn prices of $\$ 0.12, \$ 0.20$, and $\$ 0.28$ per $\mathrm{kg}$. We selected the prices to be representative of prices reported over the last decade (USDA-NASS, 2019).

Using the expected yield estimates obtained with our preferred model, LRSP2, expected net returns are calculated from equation (1) under the different price scenarios defined above. Table 2 shows the profit-maximizing nitrogen rates, yields, and net returns for the different assumed prices. The expected profit-maximizing nitrogen rates ranged from 162 to $197 \mathrm{~kg} / \mathrm{ha}$ depending on the price scenario. ${ }^{6}$

For these nitrogen rates, the corresponding expected corn yields vary from 9,620 to 9,820 kg/ha. These expected yields are equivalent to 153-156 bu/acre and are close to the average corn yield of $155 \mathrm{bu}$ /acre reported in the northeastern Colorado region by the National Agricultural Statistics Service (Meyer et al., 2017). For this specific corn average, the nitrogen fertilizer recommendation of the Colorado Extension Service-which follows a yield-based algorithm developed by the University of Nebraska-would have been of $145 \mathrm{~kg} / \mathrm{ha}$.

Although there are no official statistics about how much nitrogen on average farmers use for irrigated no-tillage continuous-corn in northeastern Colorado, previous literature (e.g. Delgado and Bausch, 2005) and corn trials conducted by Colorado State University (e.g. CSU, 2019) indicate a common use of at least $240 \mathrm{lb} /$ acre of nitrogen for conventional tillage systems. This rate corresponds to $269 \mathrm{~kg} / \mathrm{ha}$ of nitrogen, that when compared to our profit-maximizing estimates, translates as an excess use of approximately $72-107 \mathrm{~kg} / \mathrm{ha}$ of nitrogen in the study region. At an average price of $\$ 0.96$ per $\mathrm{kg}$ of nitrogen, this excess use would represent a loss to the producers of about $\$ 80 /$ ha. Depending on the price scenario, these losses can represent up to $8 \%$ of the expected net returns, hence significantly impacting farm profits.

\footnotetext{
${ }^{6}$ Standard errors were estimated for the expected profit-maximizing nitrogen rates and then used to construct $95 \%$ confidence intervals. These are reported in Appendix 2.
} 


\section{Summary and Discussion}

We estimate irrigated no-tillage continuous-corn yield response functions to nitrogen using data from a long-term study of corn yields conducted at the Agricultural Research Development and Education Center located in Fort Collins, Colorado. For our estimation, we utilize the LRSP function of Tembo et al. (2008), and to check the robustness of our results we also estimate an alternative parameterization using an SR plateau specification. Under equivalent assumptions on the random parameters and correlation of the random effects, this alternative parameterization performs as good as the classic LRSP. We suggest the SR specification as a useful robustness check for the frequentist estimation of plateau-type production functions with stochastic variations. The availability of various estimation approaches allows the researcher to check the stability and robustness of parameter estimates, and in the specific case of non-linear models, it helps avoid local optima.

Results show the expected profit-maximizing nitrogen rates range from 162 to $197 \mathrm{~kg}$ per hectare depending on the price scenario. When compared to the reported local use of nitrogen $(269 \mathrm{~kg} / \mathrm{ha})$, our estimates and the prospective Colorado Extension recommendation suggest farmers overfertilize the corn crop in the study area. Overfertilization and excess nitrogen use not only cause economic losses to farmers, but they also exact environmental costs on society (Williamson, 2011).

Delgado and Bausch (2005) report nitrogen-leaching problems related to the excess use of nitrogen in northeastern Colorado. This excessive use of fertilizer can be attributed in part to the common use of yield-based methods for nitrogen recommendations. These are part of the principal algorithms of most decision tool software being sold to farmers for fertilizer management (Rodriguez et al., 2019). The yield-based algorithms are based on achieving a specific corn yield goal such that if a farmer wants more corn bushels per acre, he needs to apply more nitrogen (Camberato, 2012). Such algorithms often disregard the existence of a yield plateau and von Liebig's Law of the Minimum. Thus, avoiding excess nitrogen applications, and promoting alternative practices such as applying nitrogen in phase with crop demand should be encouraged in the area.

Naturally, our results are conditioned on the empirical situation at hand and may not hold for all data. But as a general rule, this study indicates that the SR stochastic plateau production function is a useful approach for measuring yield response. Future research could apply this alternative parameterization along the LRSP to other crops and locations to determine optimal input rates.

Acknowledgments. The authors would like to thank USDA-ARS personnel in Fort Collins, Colorado, especially Dr. Ardell D. Halvorson, who collected grain yield data from 2001 to 2013. We are also thankful for the useful comments and suggestions from three anonymous reviewers. All remaining errors are ours.

Financial Disclosure. This work was supported by Virginia Tech Cooperative Agreement Number 58-3012-7-007 with USDA/ARS; and by Hatch Project VA 136247 Regional project NC-1034.

Conflicts of Interest. None declared.

\section{References}

Biermacher, J.T., B.W. Brorsen, F.M. Epplin, J.B. Solie, and W.R. Raun. "Economic Potential for Precision Agriculture Based on Plant Sensing Technology." Agricultural Economics 40(2009):397-407.

Boyer, C.N., J.A. Larson, R.K. Roberts, A.T. McClure, D.D. Tyler, and V. Zhou. "Stochastic Corn Yield Response Functions to Nitrogen for Corn After Corn, Corn After Cotton, and Corn After Soybeans." Journal of Agricultural and Applied Economics 45,4(2013):669-81.

Boyer, C.N., J.A. Larson, R.K. Roberts, A.T. McClure, and D.D. Tyler. "Farm-Level Corn Irrigation in Tennessee: The Impact of Field Size and Energy Cost on Profitability." Agricultural Systems 127(2014):61-9.

Boyer, C.N., J.A. Larson, R.K. Roberts, A.T. McClure, D.D. Tyler, and S.A. Smith. "Effects of Recent Corn and Energy Prices on Irrigation Investment in a Humid Region." Journal of Agricultural and Applied Economics 47,1(2015):105-22. 
Bullock, D.G., and D.S. Bullock. "Quadratic and Quadratic-Plus-Plateau Models for Predicting Optimal Nitrogen Rate of Corn: A Comparison.” Agronomy Journal 86(1994):191-5.

Camberato, J. A Historical Perspective on Nitrogen Fertilizer Rate Recommendations for Corn in Indiana (1953-2011). West Lafayette, IN: Purdue Extension, 2012. Internet site: https:/extension.purdue.edu/extmedia/AY/AY-335-W.pdf (Accessed June 04, 2020).

Cerrato, M.D., and A.M. Blackmer. "Comparison of Models for Describing Corn Yield Response to Nitrogen Fertilizer." Agronomy Journal 82(1990):138-43.

Colorado State University CSU. Technical Report Making Better Decisions 2019 Colorado Corn Variety Performance Trials TR 19-5. Internet site: https://webdoc.agsci.colostate.edu/csucrops/reports/corn/cornreport_2019.pdf (Accessed June 04, 2020).

Delgado, J.A., and W.C. Bausch. "Potential Use of Precision Conservation Techniques to Reduce Nitrate Leaching in Irrigated Crops." Journal of Soil and Water Conservation 60,6(2005):379-87.

Greene, W.H. Econometric Analysis. 8th ed. New York: Pearson, 2017.

Harmon, X., C.N. Boyer, D.M. Lambert, J.A. Larson, and C.O. Gwathmey. "Comparing the Value of Soil Test Information Using Deterministic and Stochastic Yield Response Plateau Functions." Journal of Agricultural and Resource Economics 41,2(2016):307-23.

Laporte, M.F., L.C. Duchesne, and S. Wetzel. "Effect of Rainfall Patterns on Soil Surface $\mathrm{CO}_{2}$ Efflux, Soil Moisture, Soil Temperature and Plant Growth in a Grassland Ecosystem of Northern Ontario, Canada: Implications for Climate Change." BMC Ecology 2,1(2002):10.

Maddala, G.S., and ED. Nelson. "Maximum Likelihood Methods of Markets in Disequilibrium." Econometrica 42(1974):1013-30.

Makowski, D., and M. Lavielle. "Using SAEM to Estimate Parameters of Models of Response to Applied Fertilizer." Journal of Agricultural, Biological, and Environmental Statistics 11,1(2006):45-60.

Makowski, D., and D. Wallach. "It Pays to Base Parameter Estimation on a Realistic Description of Model Errors." Agronomie 22(2002):179-89.

Meyer, B., R. Ott, L. Lohrenz, S. Gunn, C. Brokmeyer, K. McBride, and J. Schmidt. Colorado Agricultural Statistics 2017. Tech. rep., United States Department of Agriculture, 2017.

Ouedraogo, F., and B.W. Brorsen. "Hierarchical Bayesian Estimation of a Stochastic Plateau Response Function: Determining Optimal Levels of Nitrogen Fetilization.” Canadian Journal of Agricultural Economics 66,1(2017):87-102.

Roberts, D.C., B.W. Brorsen, J.B. Solie, and W.R. Raun. "The Effect of Parameter Uncertainty on Whole-Field Nitrogen Recommendations from Nitrogen-Rich Strips and Ramped Strips in Winter Wheat.” Agricultural Systems 104(2011):307-14.

Rodriguez, D.G.P., D.S. Bullock, and M.A. Boerngen. “The Origins, Implications, and Consequences of Yield-Based Nitrogen Fertilizer Management.” Agronomy Journal 111,2(2019):725-35.

Taylor, K.W., F.M. Epplin, B.W. Brorsen, B.G. Fieser, and G.W. Horn. "Optimal Grazing Termination Date for DualPurpose Winter Wheat Production.” Journal of Agricultural and Applied Economics 42(2010):87-103.

Tembo, G., B.W. Brorsen, F.M. Epplin, and E. Tostão. “Crop Input Response Functions with Stochastic Plateaus.” American Journal of Agricultural Economics 90,2(2008):424-34.

Tumusiime, E., B. Wade Brorsen, J. Mosali, J. Johnson, J. Locke, and J.T. Biermacher. "Determining Optimal Levels of Nitrogen Fertilizer Using Random Parameter Models." Journal of Agricultural and Applied Economics 43,4(2011):541-52.

United States Department of Agricultural National Agricultural Statistics Service USDA NASS. Agricultural Prices. Internet site: https://www.nass.usda.gov/Charts_and_Maps/Agricultural_Prices/pricecn.php (Accessed December 14, 2018).

Williamson, J.M. "The Role of Information and Prices in the Nitrogen Fertilizer Management Decision: New Evidence from the Agricultural Resource Management Survey." Journal of Agricultural and Resource Economics 36,3(2011):552-72. 


\section{Appendix 1}

Table A1. Random effects covariance and correlation matrix of Models LRSP2 and SR2

\begin{tabular}{|c|c|c|c|c|c|c|}
\hline & \multicolumn{3}{|c|}{ LRSP2 } & \multicolumn{3}{|c|}{ SR3 } \\
\hline $\operatorname{cov}\left(u_{t}, \omega_{t}, \nu_{t}\right)$ & \multicolumn{3}{|c|}{$\left(\begin{array}{cc}\sigma_{u}^{2} & \sigma_{u \omega} \sigma_{u v} \\
\sigma_{u \omega} & \sigma_{\omega}^{2} \sigma_{\omega v} \\
\sigma_{u v} & \sigma_{\omega v} \sigma_{v}^{2}\end{array}\right)$} & \multicolumn{3}{|c|}{$\left(\begin{array}{ccc}\sigma_{u}^{2} & \sigma_{u \omega} & \sigma_{u v} \\
\sigma_{u \omega} & \sigma_{\omega}^{2} & \sigma_{\omega v} \\
\sigma_{u v} & \sigma_{\omega v} & \sigma_{v}^{2}\end{array}\right)$} \\
\hline Estimated Results & $\left(\begin{array}{l}310,455 * * * \\
(94,043) \\
675.76 \\
(716.52) \\
296,931 * * * \\
(94,295)\end{array}\right.$ & $\begin{array}{c}- \\
- \\
39.87 * \\
(12.75) \\
1,376 \\
(1,057)\end{array}$ & $\begin{array}{c}- \\
- \\
- \\
413,414 * * * \\
(110,323)\end{array}$ & $\left(\begin{array}{l}347,167 * * * \\
(92,964) \\
402.83 \\
(582.64) \\
-3,257 \\
(2,664)\end{array}\right.$ & $\begin{array}{c}- \\
- \\
34.90 * * * \\
(9.46) \\
-127.96 * * * \\
(36.58)\end{array}$ & $\begin{array}{l}- \\
- \\
- \\
- \\
564.55 * * * \\
(172.18)\end{array}$ \\
\hline Correlation Matrix & $\left(\begin{array}{c}1 \\
0.19 \\
0.83\end{array}\right)$ & $\begin{array}{l}0.19 \\
1 \\
0.34\end{array}$ & $\left.\begin{array}{c}0.83 \\
0.34 \\
1\end{array}\right)$ & $\left(\begin{array}{l}1 \\
0.12 \\
-0\end{array}\right.$ & $\begin{array}{lc} & 0.12 \\
2 & 1 \\
.23 & -0.91\end{array}$ & $\left.\begin{array}{c}-0.23 \\
-0.91 \\
1\end{array}\right)$ \\
\hline
\end{tabular}

Notes: Standard errors are in parenthesis for the corresponding covariance matrices. We used bootstrapping techniques to obtain consistent estimates of the corresponding standard errors for both models.

${ }^{\star \star \star}$ Significant at the 0.01 level.

\section{Appendix 2}

Table A2. 95\% confidence intervals of the profit-maximizing nitrogen rates

\begin{tabular}{|c|c|c|c|c|c|c|}
\hline \multirow{3}{*}{$\begin{array}{l}\begin{array}{l}\text { Corn } \\
\text { prices }\end{array} \\
(\$ / \mathrm{kg})\end{array}$} & \multicolumn{6}{|c|}{ Nitrogen prices $(\$ / \mathrm{kg})$} \\
\hline & \multicolumn{2}{|c|}{$\$ 0.72$} & \multicolumn{2}{|c|}{$\$ 0.96$} & \multicolumn{2}{|c|}{$\$ 1.20$} \\
\hline & LRSP & SR & LRSP & SR & LRSP & SR \\
\hline$\$ 0.12$ & {$[165.27,186.42]$} & {$[159.52,178.81]$} & {$[154.73,181.25]$} & {$[157.22,171.55]$} & {$[149.69,173.43]$} & {$[148.79,170.89]$} \\
\hline$\$ 0.20$ & {$[176.19,201.83]$} & {$[162.6,191.13]$} & {$[165.87,197.75]$} & {$[160.66,184.28]$} & {$[167.65,184.03]$} & {$[161.69,176.63]$} \\
\hline$\$ 0.28$ & {$[183.46,211.45]$} & {$[173.35,188.93]$} & {$[178.43,202.04]$} & {$[170.33,184.56]$} & {$[172.75,196.36]$} & {$[160.74,187.6]$} \\
\hline
\end{tabular}

Cite this article: Villacis AH, Ramsey AF, Delgado JA, and Alwang JR (2020). Estimating Economically Optimal Levels of Nitrogen Fertilizer in No-Tillage Continuous Corn. Journal of Agricultural and Applied Economics 52, 613-623. https:// doi.org/10.1017/aae.2020.23 